\title{
Developing Custom Hardware to Teach Digital Design Courses: Added Value or Added Headache?
}

Prof. Kevin P. Pintong, Oregon Institute of Technology

Kevin Pintong is an assistant professor at Oregon Institute of Technology in Klamath Falls, Oregon.

Mr. Alexander Hogen, Oregon Institute of Technology

Alexander Hogen is a Firmware Engineer. He has been a user, tester, and creator of hardware platforms for education at Oregon Institute of Technology. 


\title{
Developing Custom Hardware to Teach Digital Design Courses: Added Value or Added Headache?
}

\author{
Kevin Pintong \\ Alexander Hogen
}

\begin{abstract}
Instructors for digital logic and design courses have a wide variety of FPGA development kits to choose from. Should the instructor choose a commercial product or develop their own system? Is there added value to custom hardware? Two programmable logic device based development kits were designed, manufactured, and used in the instruction of Digital Logic I, Digital Logic II, and Digital System Design I at Oregon Institute of Technology. In this paper, we review commercial based offerings versus our custom hardware from both the pedagogical and value perspectives. Three use cases are evaluated- commercially available, student built, and custom contract manufactured development kits. We also outline problems that an instructor may come across in developing their own programmable logic development kit.
\end{abstract}

\section{Focus}

With a wide variety of FPGA development boards available, an instructor may consider developing their own board or using a commercial off the shelf (COTS) solution. There are three options we will evaluate.

1. Use a commercial board.

2. Assemble a custom-designed board with students as part of the course.

3. Design a custom board, but have it commercially assembled.

The first option is the most common. Not only are commercial offerings reliable, but they also offer associated materials such as tutorials and pre-fabricated assignments. However, commercial offerings come pre-assembled, so students may not have complete insight into how boards are designed or assembled. The latter two differ in the time required in lab with students, but are otherwise very similar. At Oregon Institute of Technology, all three possible cases have been implemented. This paper will outline what other instructors should consider when implementing custom or commercial development kits.

While many newer boards are built around a system on a chip (SoC) device, we will focus on the use of development boards in digital logic and digital system design courses. Since Xilinx and Intel Programmable Solutions Group (PSG) are the two major vendors for programmable logic devices (PLDs), this paper will also focus on boards featuring products from these two vendors. While Actel and Lattice are alternate options, there are more resources available for Xilinx and Intel PSG for faculty members.

Some key aspects of PLD development board selection covered in this paper include the following. 
- Contribution to student learning outcomes - Does the board contain all the components needed to complete the laboratory assignments?

- PLD vendor - Does one want to use Xilinx with ISE/Vivado, or Intel PSG with Quartus?

- Existing materials available - Are there existing lesson plans or laboratory assignments available?

- Cost - How cost sensitive? Is this something purchased by the department or students?

- Time - How much time is traded off for lower cost boards?

- Quality - Will the boards consistently work, or will they need to be debugged continuously?

- Support - Who supports this final product? The faculty member or an external vendor?

- Continued availability and obsolescence - Will this product be available long term?

\section{Learning Outcomes}

Student learning outcomes should be the primary guide when evaluating a hardware options. Some additional learning outcomes can be achieved with custom boards assembled by the students.

With a custom board assembled as part of the course, students can learn about how to interpret a schematic, PCB layout, and bill of materials. Students can also have hands-on experience understanding what components look like and how they are connected together. An instructor could also add a prototyping area so that students have to wire components to the board and learn how to map them to the FPGA. These are the additional outcomes that can be achieved through custom design.

Soldering skills are another additional outcome. Using a custom board designed for students to assemble in lab provides an extended period of time to improve surface mount and through hole soldering skills. It is still possible to integrate soldering into a course using a commercial PLD board by giving students an add-on board to assemble. This may be a convenient alternative to achieve the same goal. The impacts of soldering and assembly on time and quality with custom boards is discussed in Section 3.

\section{Time and Quality}

It is important to remember that the main objective in choosing a board is to enhance and support the learning process. Learning outcomes for a particular course should determine whether it is worth it for an instructor to design, develop, and test boards. For a lower-level introduction to digital logic course, pre-fabricated boards may be a better use of time.

Lower-quality hardware can be an issue when using custom-built boards. In a higher level course, hardware debugging may in fact add to student learning. By building boards themselves, students can understand the design process, learn how to solder, read documentation, and better understand the relationship among components in the design. Additionally, students can understand how to debug their own boards, which is very valuable experience to have. 
Placing small components such as 0603 resistors, 0805 LEDs, and a 144-pin TQFP package is a difficult process for students attempting to solder for the first time. Because of this, there may be shorts, unconnected components, and other flaws. Even using a contract manufacturer will not always result in the same level of quality. In the manufacture of one of our designs, the Sidewinder board, the contract manufacturer placed the LEDs backwards and shipped defective microcontroller devices. Both the student and faculty member need to be willing to spend additional time verifying that boards meet a minimum viable standard.

\section{Custom-Built Boards}

With learning outcomes, time requirements, and quality standards associated with hardware platforms in mind, we will present points to observe if implementing a custom board hardware option. Using a custom hardware platform has its advantages and disadvantages, whether it be designed from scratch or based off of an existing open-source design. Some advantages of custom hardware observed in Oregon Institute of Technology courses include the following.

- Qualitatively better student engagement through the entire class when students assemble their own board

- Improved understanding of how components such as LEDs, resistors, buttons, EEPROM, and oscillators are connected to the FPGA or CPLD device

- Qualitatively improved understanding of circuit characteristics

- Incorporates soldering of surface mount and through-hole components

- Incorporates interpretation of schematics, PCB layouts, and bill of materials.

- Students can see the design from building the board through to programming the board, delivering a better systems level understanding of an embedded system

However, some disadvantages include:

- Significantly higher instructor workload in design

- Significantly higher instructor workload in lab

- Increased time spent on soldering, which may not be considered value added

Students will almost certainly need additional assistance assembling and setting up the custom hardware and if guidance is not available then custom hardware does nothing to improve the learning experience. If an instructor is willing to take on an additional workload and the coursework can include hands-on PCB assembly, using a custom board can be a very rewarding experience for students.

If a custom board seems impractical, consider commercial options available with either Intel PSG or Xilinx devices. These options are discussed in Section 5.

\subsection{Design Considerations}

When designing a custom board, consider the following points so the resulting product suits your teaching goals and caters to student's learning needs. 


\section{a) CPLD vs. FPGA}

Some instructors choose to limit students to a CPLD such that the student must efficiently code the design. Others feel that the more advanced features of an FPGA device such as digital clock management, phase lock loops, and soft core processors are more valuable. W suggest that an FPGA device is preferable and more flexible. Concise, optimized logic can still be taught by setting appropriate assignment constraints while using a more flexible FPGA.

b) Compatibility with vendor design software

As an example, the Spartan 6 was used in the design of OwlBoard. The software used to program Spartan 6 devices, ISE, was deprecated by Xilinx at version 14.7 in October 2013. Spartan 7 devices were not yet available in a surface mount package during design of the OwlBoard. While this does not seem like a major problem, note that Xilinx ISE 14.7 does not support SystemVerilog. Also note that the design flow in the subsequent Xilinx software tool suite, Vivado, has changed dramatically.

Consider that when building your own board, you will need to redesign your board every 5-10 years in order to remain up to date with current technology.

c) FPGA/CPLD Device Configuration

Intel products can be programmed using different tools. For those designing a custom board and desiring an on-board programmer, an example USB programmer is described at [1]. The design emulates a USB byte blaster using a PIC18F14K50, and can be integrated into your custom design.

Those desiring an external programmer can buy a low cost officially supported programmer for $\$ 50$ from Terasic, the Intel PSG preferred board vendor [2].

For those really wanting to save money, a not-so-genuine USB byteblaster can be found for \$3-\$10 on websites such as Ebay and Amazon.

With Xilinx FPGAs, you must use an official programming cable or an FTDI JTAG adapter. Official cables are available through Digilent Inc. These cables are expensive at $\$ 59$ for the USB to JTAG cable, since they are the only ones which work directly with Xilinx Impact [3].

Alternatively, you can use an FT232H adapter available through FTDI [4]. This multipurpose adapter can be used as an I2C, SPI, UART, and JTAG converter. Open source software, xc3sprog, can program the FPGA outside of Xilinx Impact [5]. However, to do this you will need to take the bit file generated by Xilinx ISE and program it to the FPGA using xc3sprog using a command line. This could be considered a disadvantage to using a custom designed Xilinx board. However, the cost of the FT232H adapter is $\$ 12-20$, so for cost conscious applications, using the FT232H or FT2232H adapter is advantageous [4]. Note that the FT2232H is a dual channel version of the FT232H, so those wishing to program and use a UART interface at the same time should consider the FT2232H instead.

d) Number of switches and LEDs

Make sure that you have a sufficient number of LEDs and buttons or switches on the custom board to cover your existing laboratory assignments. Although existing labs were checked, 
it was later found that some labs needed additional buttons, switches or LEDs not available on the new board. For instance in one Digital Logic lab, there were an insufficient number of switches available so, to be compatible with the hardware, a carry input for an adder design had to be removed from the assignment.

e) Active-high vs. active-low

When designing a board, it is easier for students understand logic levels when LEDs are wired as active-high devices. If the anode of an LED was connected to VCC and the cathode was connected to a pin on the FPGA (through a resistor, of course.), then the LED is in an active-low configuration. However, students may be confused if they expect a light to turn on in response to a logic ' 1 ' output. This can also be used as a lesson in active high and active low logic. If one wants to keep the interface straightforward for students they can wire LEDs in an active-high configuration.

For a switch or button, it is easy to use the internal weak pull-up or pull-down of the CPLD or FPGA device. This saves both board space and the cost of an extra resistor. Using the pullup resistor, an FPGA pin would read a normally-open pushbutton as VCC ( logic '1') until the button is pressed where the device would then see a '0' as the FPGA/CPLD pin is connected to ground.

f) Switch and button bounce

In a previous revision of the Digital Logic course, the DE0 or DE1-SoC FPGA development boards from Terasic were used. The switches on those boards are bouncy, but were useful illustrations of switch bounce. However, there are de-bouncing Schmitt triggers on the boards' three pushbuttons so as long as switches were used as level-sensitive and not edgesensitive inputs, switch de-bouncing could be covered in a subsequent course [6]. However, the switches chosen for the OwlBoard were so noisy that they required switch de-bouncing. If you rely on not teaching de-bounce concepts in your course, test the switches and buttons beforehand to verify that they work well enough without de-bounce or consider adding de-bouncing hardware to your board.

\section{g) Oscillator frequency}

While it is tempting to use a fast oscillator, remember that your student may need to perform clock division. Choose an oscillator that would result in a reasonable register size when the student writes a clock divider, especially if using a CPLD device with limited logic elements. If using an FPGA, this is typically not as much of a concern.

\section{h) Part quantities}

To ensure there will be enough PCBs and parts for the course, double the number of components needed per student. Students new to soldering and PCB assembly frequently damage components. The instructor should consider purchasing additional components, especially smaller surface mount components. These components tend to be misplaced quickly. The LEDs also tend to be placed backwards or be overheated while soldering.

i) Assembly time 
While an experienced technician or engineer could completely assemble the OwlBoard in less than 15 minutes, it took students 3-12 hours to complete the board. Ideally, students should complete the board within a three hour lab period. However, it is important to schedule additional time outside of lab to prevent students from falling behind.

Assembly time can be reduced by using the following strategies:

- Space components farther apart on the board

- Reduce the number of decoupling capacitors

- Use larger through hole components

- Avoid no-lead surface mount

- Use components no smaller than 0805

- Have an external vendor pre-populate components

- An external vendor in China would charge \$0.04 a pin (as of 2016), so a difficult component to mount, like a TQFP-144 package, could be mounted for $\$ 5.76$

- Using this method would remove the pedagogical benefit of understanding how to mount a TQFP package, but it would also reduce time required in class, and this trade-off should be considered.

Two boards were designed at Oregon Institute of Technology. The Sidewinder was designed to be a low-cost replacement for an aging Digital Logic I course. The OwlBoard was designed to be a board that students build in class. The experiences encountered while developing and using these boards are documented in the following sections.

\subsection{Sidewinder: Board designed for outside manufacturing}

This board was originally designed by a student, Dustin Henderson, as part of a independent study project in PCB design. It was then modified for manufacturing.

With all of the troubles encountered when shipping the Sidewinder design off to be manufactured, this option is not recommended. The assembly facilities used for this board returned unreliable products. Instead of saving time by receiving the boards assembled, this option instead wasted time with attempts to fix all of the assembly errors.

\subsubsection{Pedagogical and Design Objectives}

The Sidewinder development board was designed for use in Digital Logic I and II courses at Oregon Institute of Technology. The custom board provides students a personal development board at a low price so they could work on Computer Engineering courses from home. As such, the following design goals were developed.

- Low cost

- Small form factor

- Power and programming provided through USB interface

- Arduino shield compatibility

- Large number of GPIO to connect with other systems 
- FPGA-based to add soft core processor and debugging capabilities

- Compatible with modern software tools

- Sufficient number of switches and LEDs so existing labs can be used

The final board design offers the following features:

- MAX V 5M160ZT100C5 CPLD device with 160 logic elements in TQFP package

- 10 slider switches

- Three RGB LEDs

- 12 LEDs

- One 40-pin header

- Integrated programming circuitry and micro USB connector

- Support for $1.8 \mathrm{~V}, 3.3 \mathrm{~V}$ and $5 \mathrm{~V}$ regulated supply rails

The block diagram and image of the final Sidwinder board design are shown in Figure 1 and Figure 2 respectively.

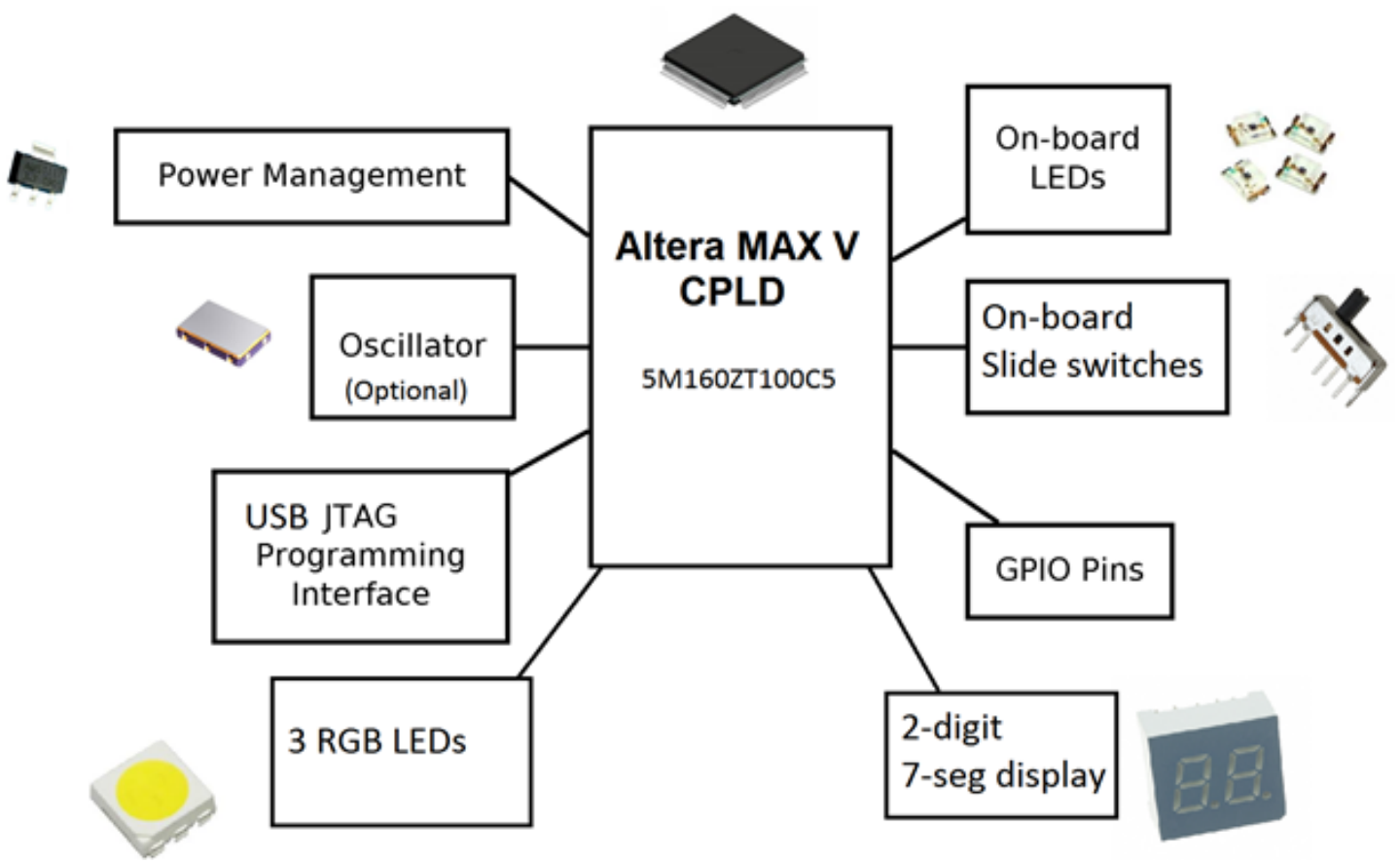

Figure 1. Sidewinder block diagram 


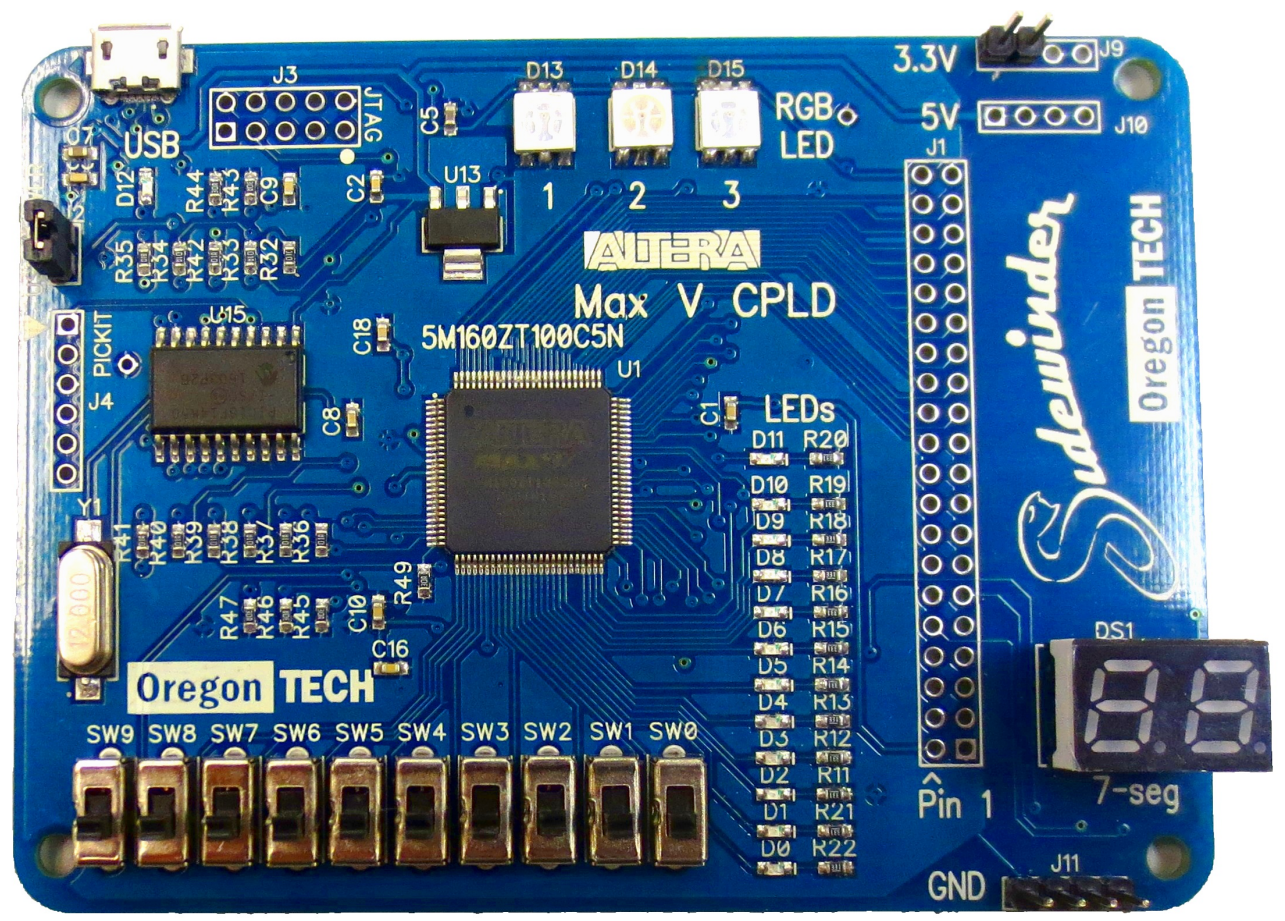

Figure 2. Sidewinder MAX V CPLD board fully assembled

\subsubsection{Costs}

The board specifications were 317 SMD pads, 68 through hole pads, 2-layers, $7.4 \mathrm{~cm}$. x 10 $\mathrm{cm}$., $1.6 \mathrm{~mm}$. thickness, HASL, and blue solder mask. With components supplied by Elecrow, assembly, fabrication of PCB, engineering fees and shipping, the total cost was $\$ 1108.91$ for 45 boards, resulting in a cost of $\$ 25$ per board.

The parts needed for each Sidewinder board are listed in Table 2. Because these boards were not going to be assembled by students, only the parts needed for each board are purchased. As mentioned in Section 4.1, if boards will be assembled by students, it is prudent to order at least twice the number of parts required.

Table 2. Sidewinder Bill of Materials

\begin{tabular}{|c|c|c|c|c|c|}
\hline RefDes & Description & Part Number & Cnt. & Unit Price & Total Price \\
\hline C1, C4, C8-C18 & & $0.1 \mathrm{uF} \mathrm{10V}$ & 13 & 0.012 & 0.156 \\
\hline C2, C3 & & $100 \mathrm{nF} \mathrm{10V}$ & 2 & 0.012 & 0.024 \\
\hline C5, C6,C7 & & $10 \mathrm{uF} \mathrm{10V}$ & 3 & 0.015 & 0.045 \\
\hline D0-D12 & & 0603 BLUE LED & 13 & 0.030 & 0.390 \\
\hline D13-D15 & & 5050 RGB LED & 3 & 0.050 & 0.150 \\
\hline DS1 & Lumex & 696-LDD-E2802RD & 1 & 0.400 & 0.400 \\
\hline
\end{tabular}

Continued on next page 
Table 2 - continued from previous page

\begin{tabular}{|c|c|c|c|c|c|}
\hline Ref. & Description & Part No. & Cnt. & Unit Price & Total Price \\
\hline 7-seg socket & & SA103000 & 1 & 0.300 & 0.300 \\
\hline $\mathrm{J} 1$ & & $\begin{array}{l}\text { Male } 20 \times 20.1 " \\
\text { header }\end{array}$ & 1 & & \\
\hline $\begin{array}{c}\text { J2(USB } \\
\text { POWER) + } \\
\text { Jumper }\end{array}$ & & Male $2 \times 10.1 "$ header & 1 & 0.040 & 0.040 \\
\hline $\mathrm{J} 5$ & & ZX62D-B-5PA8 & 1 & 0.350 & 0.350 \\
\hline J9, J11 & & Male $2 \times 10.1 "$ header & 2 & 0.080 & 0.160 \\
\hline R3, R6, R9, R35 & & $\begin{array}{c}\text { 1K Ohm 1\% 1/8 } \\
0603\end{array}$ & 4 & 0.010 & 0.040 \\
\hline $\mathrm{R} 23, \mathrm{R} 24$ & & 0 Ohm $1 \%$ 1/8 0603 & 12 & 0.010 & 0.120 \\
\hline R32 & & $\begin{array}{c}\text { 10K Ohm 1\% 1/8 } \\
0603\end{array}$ & 1 & 0.010 & 0.010 \\
\hline $\begin{array}{l}\text { R33-R34, } \\
\text { R36-R42 }\end{array}$ & & $\begin{array}{c}100 \mathrm{Ohm} 1 \% \\
0603\end{array}$ & 9 & 0.010 & 0.090 \\
\hline R43-R49 & & $\begin{array}{c}200 \mathrm{Ohm} 1 \% 1 / 8 \\
0603\end{array}$ & 6 & 0.010 & 0.060 \\
\hline SW0-SW9 & $\begin{array}{c}\text { SPDT } \\
\text { switch } \\
\text { COMAX }\end{array}$ & $\begin{array}{c}\text { SS-12D07-VG } 4 \text { NS } \\
\text { GA PA }\end{array}$ & 10 & 0.150 & 1.500 \\
\hline U1 & Altera & 5M160ZT100C5N & 1 & 3.700 & 3.700 \\
\hline U13 & AMS & AMS1117-3.3 & 1 & 0.100 & 0.100 \\
\hline U14 & AMS & AMS1117-1.8 & 1 & 0.100 & 0.100 \\
\hline U15 & $\begin{array}{l}\text { MICRO- } \\
\text { CHIP }\end{array}$ & $\begin{array}{l}\text { PIC18F14K50-I/SO- } \\
\text { ND }\end{array}$ & 1 & 2.850 & 2.850 \\
\hline Y1 & & $\begin{array}{c}\text { ABLS-12.000MHZ- } \\
\text { B4-T }\end{array}$ & 1 & 0.150 & 0.150 \\
\hline FUSE1 & Bel Fuse & 0ZCG0050AF2C & 1 & 0.100 & 0.100 \\
\hline $\begin{array}{l}\text { R2, R5, R8, } \\
\text { R10-R22, R51, } \\
\text { R53-R57 }\end{array}$ & $\begin{array}{l}\text { for LEDs } \\
\& \text { RGB } \\
\text { LEDs }\end{array}$ & $\begin{array}{c}\text { RES SMD } 330 \text { OHM } \\
1 \% 1 / 8 \mathrm{~W} 0603\end{array}$ & 22 & 0.008 & 0.176 \\
\hline \multirow[t]{2}{*}{$\mathrm{R} 1, \mathrm{R} 4, \mathrm{R} 7$} & & $\begin{array}{c}\text { RES SMD } 500 \text { OHM } \\
1 \% 1 / 8 \mathrm{~W} 0603\end{array}$ & 3 & 0.010 & 0.030 \\
\hline & & & & Total & 11.041 \\
\hline
\end{tabular}


Table 1. Sidewinder Production Costs

\begin{tabular}{|lrr|}
\hline Type & Description & Cost \\
\hline PCB fabrication & $\$ 60.75$ \\
\hline Stencil & & $\$ 18.00$ \\
\hline Assembly & 317 SMD pads @ 0.03 ea. for 45 boards & $\$ 428.95$ \\
\hline & 68 through-hole pads @ 0.04 ea. for 45 boards & $\$ 122.40$ \\
\hline Discounts & 10\% off for quantity 45 - 55 & $-\$ 123.21$ \\
\hline Engineering fee & $\$ 10.00$ \\
\hline Components sourced by Elecrow & $\$ 496.85$ \\
\hline Shipping & $\$ 28.00$ \\
\hline & \\
\hline Total & $\$ 1108.91$ \\
\hline
\end{tabular}

\subsubsection{Lessons Learned in Design}

During the design and production stages of the project, there were many problems. First, the original FPGA chosen for the device was unavailable for an additional 6 months so the board had to be redesigned with a lower-end CPLD, removing many additional features. When the boards were received, the RGB LEDs were installed backwards, some PIC processors were defective, and some switches fell off the board.

In order to fix these issues, additional costs were incurred. The RGB LEDs were de-soldered from the boards by hand. In total there were three RGB LEDs per board, so a total of 135 RGB LEDs were removed, reoriented, and re-soldered to the board. Some LEDs were damaged in the process so some spare RGB LEDs were used.

When the boards were tested, it was found that some of the PIC18F14K50 processors could not be programmed by the PICKit3. Out of the 45 boards, there were approximately four defective processors, and these were replaced. The cause of failure was not determined.

Another problem was the switch specification. The original design called for an authentic COMAX switch. In order to cut costs, lower quality switches were substituted. These lowerquality switches occasionally malfunctioned and had to be replaced. Approximately 10 switches needed to be replaced, but there are also switches that continually malfunction.

There was also one board which was scrapped since there were too many hardware issues it was uneconomical to repair.

One important note is the use of usb micro connectors. It is recommended that the designer use a USB mini or USB B connector, as usb micro connectors can be fragile in the lab setting.

These are the types of issues that an instructor may come across when sending a board design to be manufactured and assembled. Some of these issues could be resolved over time by being more careful with the supplier and design. As can be seen from the problems experienced above, it is a more efficient use of time and money to use a commercial offering 
if building the board is not a pedagogical part of the course. Remember that the instructor is liable if there are any issues that arise with the custom third party built boards. If we compare the cost of our board at $\$ 25$ to the lower cost commercial offerings at $\$ 55$ for the Terasic DE0-Lite board (Intel PSG device) or at $\$ 50$ for the Numato Mimas V2 (Xilinx device), we will see that the commercial offerings are more reliable and provide a larger number of features.

\subsection{OwlBoard: Board designed for in-class assembly}

The OwlBoard was developed for use in a Digital System Design I course. The existing pedagogy was outdated, using wire wrapping tools and a discontinued CPLD device. It was designed to teach students how to solder both through-hole and surface mount components as well as wire wrapping. More importantly, the hardware platform was designed so that students would understand component connectivity. The Digital System Design I course at Oregon Institute of Technology does place emphasis on soldering, whereas other institutions or courses may not. The board building process is a one week activity primarily designed to increase student engagement.

The final board design features the following components:

- Spartan 6 TQFP 144 FPGA

- Four push buttons

- Eight LEDs

- One $50 \mathrm{MHz}$ oscillator

- Two 40-pin headers

- USB programming circuitry

- Support for $3.3 \mathrm{~V}$ and $5 \mathrm{~V}$ power

- Prototyping area for students to add additional components

\subsubsection{Pedagogical and Design Objectives}

The OwlBoard was designed to assist teaching the following concepts.

- Soldering of surface mount and through-hole components

- Understanding of schematic, layout, and BOM

- Understanding of how external components are connected to FPGA

- Understand the need for current limiting resistors for LEDs and calculate a proper value

- Place a button, seven-segment display, or other device into a prototyping area, wire it to the programmable logic device, and successfully program the PLD to interface with the new component(s).

With these teaching objectives, there were some specific objectives the board design had to achieve. These design objectives are listed below.

- The board should be easy to solder

- The board should be sufficiently low-cost to account for mistakes 
- The board should have a prototyping area

The OwlBoard is based on a modified open source Numato Mimas board, which is mentioned in Section 5.2. The OwlBoard builds on this foundation by changing the programming circuitry, rearranging the board to a more beginner-friendly layout, and adds a through-hole prototyping area, according to the above design objectives. The third iteration of the OwlBoard design is outlined in Figure 3 and Figure 4 shows the final assembled product.

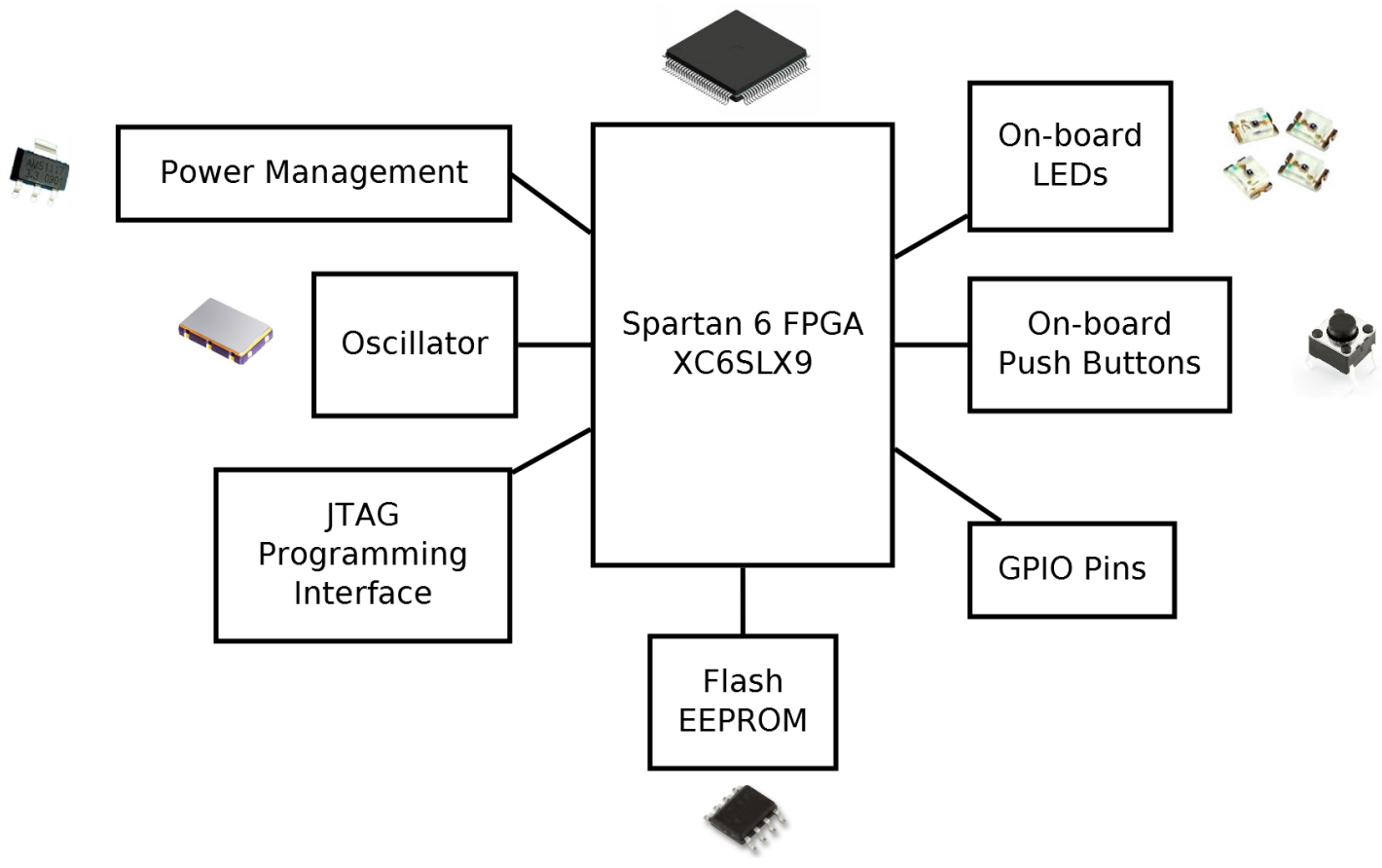

Figure 3. OwlBoard block diagram 


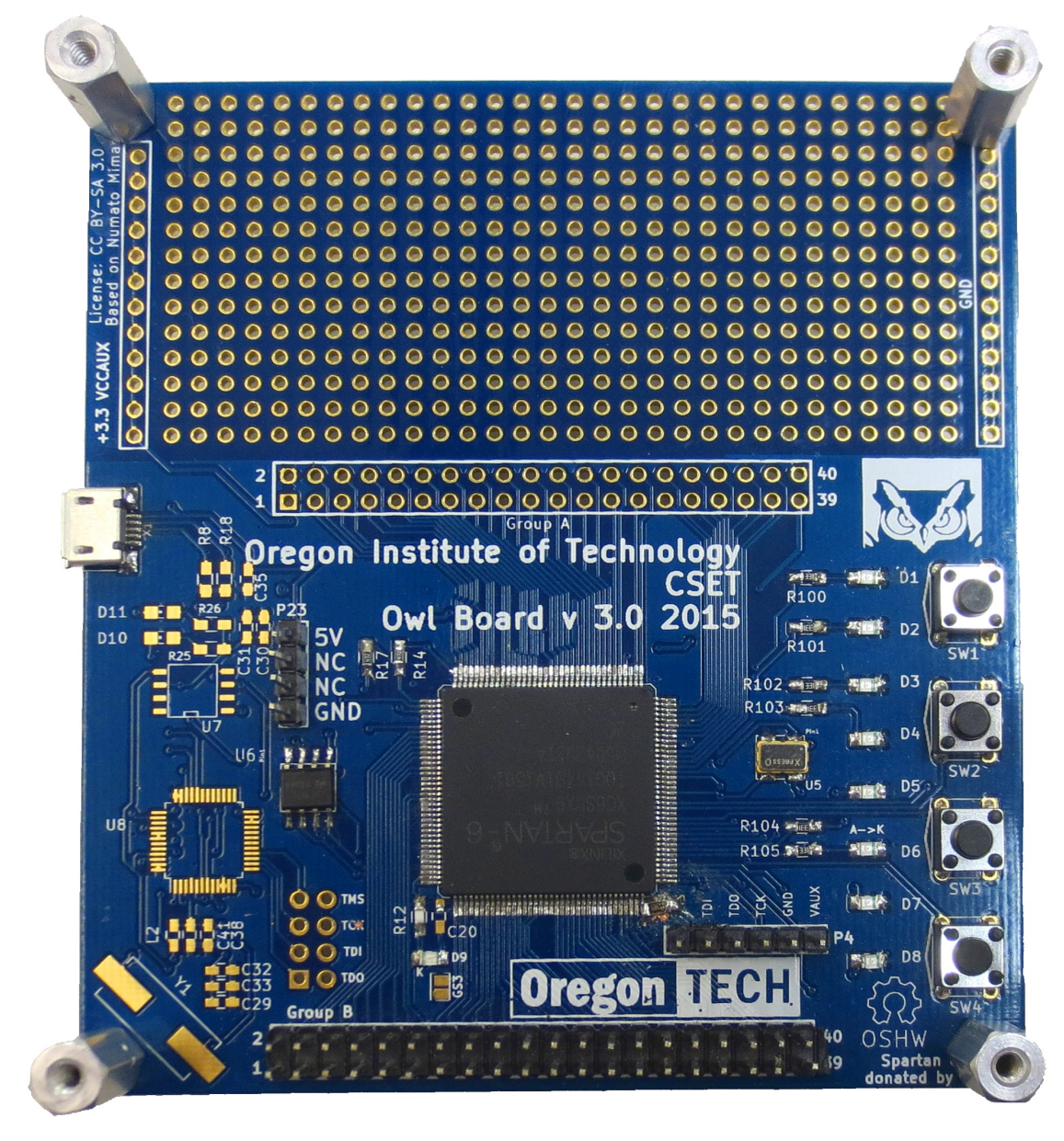

Figure 4. OwlBoard Spartan 6 FPGA board fully assembled

\subsubsection{Costs}

One benefit of developing custom boards is the reduced BOM cost through Xilinx and Intel PSG. Within reasonable specification and quantity, both companies will donate FPGA and CPLD products and chips for educational use.

Development costs for the OwlBoard were under \$200 excluding labor. This included three PCB revisions and various components. Each revision of the PCB cost approximately $\$ 35$. It is suggested to use pcbshopper.com to find the lowest cost vendor. This project used Elecrow, a Shenzhen, China based vendor.

Labor costs in development were not considered except for student labor in developing a datasheet and testing out the feasibility of building these boards. The student labor for the user guide and feasibility testing came to approximately 30 hours. Faculty labor was not considered, as development was done on personal time. A faculty member experienced in PCB design should have no problem completing a design in 120-240 hours, including prototyping and debugging. This time does not include pedagogical development. 
Final student material costs of the OwlBoard are outlined in Table 3. While the cost per board or student is only $\$ 11.25$, note that since each student is building their own board for the first time, spare components are needed, as discussed in Section 4.1. Also note that the FPGA was donated by Xilinx, so there is no cost associated with the IC. It would be prudent to order two to three times the number of components required. Note that components such as capacitors and resistors were significantly lower cost when bought by the reel.

Table 3. OwlBoard Bill of Materials

\begin{tabular}{|c|c|c|c|c|}
\hline PCB Reference & Qty. & Value & Cost & Extended Cost \\
\hline $\mathrm{C} 1$ & 1 & $47 \mathrm{uF}$ & 0.56 & 0.56 \\
\hline $\mathrm{C} 26-27$ & 2 & $15 \mathrm{pF}$ & 0.01 & 0.02 \\
\hline $\mathrm{C} 2-\mathrm{C} 4$ & 3 & $10 \mathrm{uF}$ & 0.04 & 0.12 \\
\hline C5-C25, C28-C30, C33-C35 & 27 & $0.1 \mathrm{uF}$ & 0.01 & 0.27 \\
\hline D1-D9 & 11 & LED & 0.06 & 0.66 \\
\hline P1 & 1 & CONN_2 & 0.175 & 0.175 \\
\hline P100 & 1 & GND & & 0 \\
\hline P101 & 1 & VCC AUX +3.3 V & 0 & \\
\hline $\mathrm{P} 23$ & & CONN_4 & & 0 \\
\hline P2-P3 & 2 & CONN_20X2 & 0.3 & 0.6 \\
\hline $\mathrm{P} 4$ & 1 & CONN_01X06 & 0 & \\
\hline R1, R9, R16 & 3 & $2.4 \mathrm{k} \Omega$ & & 0.01 \\
\hline $\mathrm{R} 10, \mathrm{R} 14, \mathrm{R} 15, \mathrm{R} 17$ & 4 & $4.7 \mathrm{k} \Omega$ & & 0.01 \\
\hline R8, R12, R18, R100-R107 & 11 & $330 \Omega$ & & 0.01 \\
\hline SW1-SW4 & 8 & SW_PUSH & 0.05 & 0.4 \\
\hline U1 & 1 & AMS1117 1.2 & 0.1 & 0.1 \\
\hline $\mathrm{U} 2, \mathrm{U} 3$ & 2 & AMS1117 3.3 & 0.1 & 0.2 \\
\hline U4 & 1 & XC6SLX9-2TQG144C & 0 & 0 \\
\hline U5 & 1 & FXO-HC536R & 1.25 & 1.25 \\
\hline U6 & 1 & M25P80 & 0.71 & 0.71 \\
\hline \multirow[t]{3}{*}{$\mathrm{X} 1$} & 1 & USBMICRO & 0.159 & 0.159 \\
\hline & 2 & PCBs & 3 & 6 \\
\hline & & & Total & $\$ 11.254$ \\
\hline
\end{tabular}

\subsubsection{Lessons Learned in Design}

The Spartan 6 was used in the design of OwlBoard. The software used to program Spartan 6 devices, ISE, was deprecated by Xilinx at version 14.7 in October 2013. Spartan 7 devices were not yet available in a surface mount package during design of the OwlBoard. While this 
does not seem like a major problem, note that Xilinx ISE 14.7 does not support SystemVerilog. Also note that the design flow in the subsequent Xilinx software tool suite, Vivado, has changed dramatically. This issue led to the design consideration mentioned as point ?? in Section 4.

\subsection{Summary}

When designing your board, note the type of 7-segment displays as well as the number of switches and LEDs. Pedagogically, how many switches and LEDs will you need to cover your lesson? Do you want the 7-segment to be multiplexed in order to teach multiplexing, or is the class an earlier class which would benefit from not having the multiplexed 7-segment?

Custom board development should only take place when the board will be built as part of the course. A custom board significantly improves student engagement in courses when the student is involved with building the board from scratch. A through-hole prototyping area where students are required to wire up components also improves understanding of key concepts such as current limiting resistors, pin mapping, and pull up resistors. This was used in the OwlBoard, discussed in Section 4.3. Student engagement was also qualitatively improved through the use of RGB LEDs, larger buttons and switches. Most of these options are also available on many commercial boards.

Do not design boards with the intent of saving cost. Remember that while you may see a savings when looking at the BOM, there is a great cost to repairing and supporting defective boards. Remember that this cost falls on you! The sole purpose of a development board is to support your pedagogical objectives, so design the boards to be built in class only if you see a pedagogical benefit.

\section{Commercial Offerings}

Many commercial offerings are available from a wide variety of vendors. Since some faculty would prefer students purchase their own boards, continual supply may be necessary and we will focus on offerings from established vendors. Since Xilinx and Intel PSG, the two main vendors, control a large part of the market, we will focus on products featuring their devices [7].

When exploring commercial board options, it may not be necessary to look for a board with all of the features and peripherals needed for all desired learning objectives. A custom peripheral board for a chosen commercial platform could be designed, providing the desired devices on either a proto-board or custom PCB. This option may simplify course planning and reduce the assembly complexity. However, total hardware costs may be greater than a custom board with all the needed components built in. The choice here depends on the level of handson student engagement, hardware planning and development, and commercial dependency desired. 
The following commercial offering evaluations are only considering FPGA boards and not CPLD boards. This was discussed in Section 4.1.

\subsection{Intel PSG Based Boards}

Intel PSG's preferred vendor is Terasic. In fact, most boards presented in Table 4 are from Terasic, as most independent PLD board design organizations favor Xilinx devices. You may be able to request a Terasic board donation through the Intel University Program for teaching or research purposes. The program focuses on the DE1-SoC and DE1-Nano boards and offers laboratory assignments for Digital Logic, Computer Organization, and Computer Systems classes [8]. The boards provided through this program may also eligible for an academic discount.

Table 4. Intel PSG Development Boards

\begin{tabular}{|c|c|c|c|c|c|c|c|c|c|}
\hline Board & $\$$ & IC & $\mathbf{L E}$ & Clk & $\begin{array}{l}\text { SW/ } \\
\text { BTN }\end{array}$ & LED & 7seg & VGA & Features \\
\hline $\begin{array}{c}\text { BeMicro } \\
\text { MAX10 } \\
{[9]}\end{array}$ & 30 & MAX10 & $8 \mathrm{~K}$ & $\begin{array}{c}50 \\
\mathrm{MHz}\end{array}$ & $4 /-$ & 7 & - & - & $\begin{array}{l}\text { ADC, DAC, } 8 \\
\text { MB SDRAM, } \\
\text { Accelerometer, } \\
\text { Temp Sensor, } \\
\text { Photo resistor, } \\
\text { 80-pin MEC } \\
\text { connector }\end{array}$ \\
\hline $\begin{array}{l}\text { WXEDA } \\
\text { Cyclone } \\
\text { IV [10] }\end{array}$ & 45 & $\begin{array}{c}\text { Cyclone } \\
\text { II }\end{array}$ & $12 \mathrm{~K}$ & $\begin{array}{c}48 \\
\mathrm{MHz}\end{array}$ & $4 /-$ & 4 & 4 & Yes & $\begin{array}{l}\text { IR, PS2 port, } \\
\text { beeper, } 32 \mathrm{MB} \\
\text { SDRAM, SMA } \\
\text { connector, ADC, } \\
\text { 1x } 26 \text { pin header }\end{array}$ \\
\hline $\begin{array}{l}\text { DE10- } \\
\text { Lite } \\
\text { (Terasic) } \\
\text { [11] }\end{array}$ & $55^{*}$ & $\begin{array}{c}\text { MAX } \\
10\end{array}$ & $50 \mathrm{~K}$ & $\begin{array}{c}50 \\
\mathrm{MHz}\end{array}$ & $\begin{array}{c}10 / \\
2\end{array}$ & 10 & 6 & Yes & $\begin{array}{l}\text { Arduino header, } \\
\text { Accelerometer, } \\
\text { ADC, } 64 \mathrm{MB} \\
\text { SDRAM, 40pin } \\
\text { header }\end{array}$ \\
\hline $\begin{array}{c}\text { DE0- } \\
\text { Nano } \\
\text { (Terasic) } \\
{[12]} \\
\end{array}$ & $61^{*}$ & $\begin{array}{c}\text { Cyclone } \\
\text { IV }\end{array}$ & $22 \mathrm{~K}$ & $\begin{array}{c}50 \\
\mathrm{MHz}\end{array}$ & $4 / 2$ & 8 & - & - & $\begin{array}{c}32 \text { MB SDRAM, } \\
\text { 2x 40-pin GPIO, } \\
\text { Accelerometer, } \\
\text { ADC }\end{array}$ \\
\hline $\begin{array}{c}\text { DE1- } \\
\text { Nano-SoC } \\
\text { (Terasic) } \\
{[13]}\end{array}$ & $90 *$ & $\begin{array}{c}\text { Cyclone } \\
\text { IV } \\
\text { SoC }\end{array}$ & $40 \mathrm{~K}$ & $\begin{array}{c}50 \\
\mathrm{MHz}\end{array}$ & $4 / 2$ & 8 & - & - & $\begin{array}{l}\text { SoC ARM A9, } \\
\text { Arduino header, } \\
1 \text { GB DDR3, } \\
\text { microSD, 2x } 40 \\
\text { pin header }\end{array}$ \\
\hline
\end{tabular}


Table 4 - continued from previous page

\begin{tabular}{|c|c|c|c|c|c|c|c|c|c|}
\hline Board & $\$$ & IC & $\mathbf{L E}$ & Clk & $\begin{array}{l}\text { SW/ } \\
\text { BTN }\end{array}$ & LED & 7seg & VGA & Features \\
\hline $\begin{array}{c}\text { DE0-CV } \\
\text { (Terasic) } \\
{[14]}\end{array}$ & $99 *$ & $\begin{array}{c}\text { Cyclone } \\
\text { V }\end{array}$ & $49 \mathrm{~K}$ & $\begin{array}{c}50 \\
\mathrm{MHz}\end{array}$ & $\begin{array}{c}10 / \\
6\end{array}$ & 10 & 6 & Yes & $\begin{array}{l}\text { PS2 port, } 64 \mathrm{MB} \\
\text { SDRAM, } 2 \mathrm{x} \\
\text { 40pin header }\end{array}$ \\
\hline $\begin{array}{c}\text { BeMicro } \\
\text { CV A9 } \\
{[15]}\end{array}$ & 149 & $\begin{array}{c}\text { Cyclone } \\
\text { V }\end{array}$ & $301 \mathrm{~K}$ & $\begin{array}{c}50 \\
\mathrm{MHz}\end{array}$ & $4 / 2$ & 8 & - & - & $\begin{array}{l}\text { Gigabit Ethernet, } \\
128 \text { MB DDR3 } \\
\text { SDRAM, 80-pin } \\
\text { MEC connector }\end{array}$ \\
\hline $\begin{array}{c}\text { DE1-SoC } \\
\text { (Terasic) } \\
\text { [16] }\end{array}$ & $175^{*}$ & $\begin{array}{l}\text { Cyclone } \\
\text { IV } \\
\text { SoC }\end{array}$ & $85 \mathrm{~K}$ & $\begin{array}{c}50 \\
\mathrm{MHz}\end{array}$ & $\begin{array}{c}11 / \\
4\end{array}$ & 10 & 6 & Yes & $\begin{array}{c}\text { SoC ARM A9, } \\
\text { 1GB DDR3, } \\
\text { microSD, audio, } \\
\text { IR, USB, UART, } \\
\text { Ethernet, PS2 }\end{array}$ \\
\hline
\end{tabular}

* Academic pricing

\subsubsection{Evaluation of Intel PSG Boards}

\section{BeMicro MAX10}

The BeMicro MAX10 board is very cost effective at $\$ 30$, and contains additional features such as an ADC, DAC, SDRAM, accelerometer, temperature sensor, and photo resistor [9]. However, there is a lack of buttons, switches and LEDs. Since it is such a low cost board, an instructor could pair this board with a custom PCB containing additional buttons, switches, and LEDs which would not be difficult or expensive. Students could purchase their own BeMicro MAX10 and plug into the course custom PCB. Note that continuous supplies of this board are not guaranteed so those using it should probably buy enough for a class set.

\section{WXEDA Cyclone IV}

This board can be found from a number of Chinese vendors on-line for around $\$ 45$. This board has an insufficient number of buttons, switches, and LEDs [10]. While it contains interesting features such as an IR port, SMA connector, beeper, and ADC, it is a risky choice due to possible supply issues. It would be better to spend additional money on the DE10-Lite or add an additional PCB to the BeMicro MAX10.

\section{DE10-Lite}

At $\$ 55$ academic, the DE10-Lite board from Terasic is a very good choice. It contains a sufficient number of buttons, switches, 7-segments, and LEDs for most Digital System Design or Digital Logic courses. It also contains an ADC, accelerometer, and Arduinocompatible header footprint. 
The DE0-Nano is a compact board featuring the Cyclone IV FPGA. While the compact size is convenient, most faculty will find that the board is too limited in the number of buttons, switches, LEDs, and 7-segments without adding or building an add-on board. There are only two buttons and eight LEDs on board. This could be fixed by building an add-on board that plugs into one of the two available 40-pin headers. At \$61 academic pricing, this board is not as good of a value for Digital Logic and Digital Systems Design courses as the DE1-SoC or DE0-Max10 board, which have many more built-in LEDs, switches, and buttons. This board might be a good board for students to place into their junior or senior projects, although the lower-cost BeMicro MAX10 is only \$30.

\section{DE0-CV}

This board costs more than the DE10-Lite, while providing a similar set of features. Unless one really needs the PS2 port, the DE10-Lite is a better option.

\section{BeMicro CV A9}

The BeMicro CV A9 board is not a very good choice at $\$ 149$. It does contain Gigabit Ethernet and $301 \mathrm{~K}$ logic elements. However, it has only 4 switches, 2 buttons, and 8 LEDs making it not ideal for a digital logic or digital system course.

\section{DE1-SoC}

The DE1-SoC is part of the Intel University program, and labs are available in both Verilog and VHDL [8]. The board contains many features at the \$175 academic price point. This board could be used for digital system design and digital logic courses and beyond since it contains 10 LEDs, four buttons, and four switches. In addition to this, it features a SoC with an ARM A9 processor, audio, VGA, 64 MB SDRAM, 1GB DDR3 and microSD card slot visible to the hard processor system, ethernet, USB, and UART. It also includes an IR remote [16].

\subsubsection{Intel PSG Best Value Board}

If cost is not an issue and a board for all classes in the curriculum is desired, the DE1-SoC is the best choice at an academic price of $\$ 175$. As mentioned previously, the Intel PSG University program also provides lab assignments written for this board [8]. If cost is an issue, the DE10-Lite is a good option at an academic price of $\$ 55$, containing all the peripherals needed in digital logic and digital system design. If a low-cost option is needed, the BeMicro MAX10 at $\$ 30$ is also a good choice if the instructor is willing to develop an accessory board for additional buttons, switches, LEDs, and seven-segments. These three choices represent the best value in Intel PSG based boards.

\subsection{Xilinx Based Boards}

For Xilinx based boards, Digilent is the preferred partner. Some Digilent boards are eligible for donation requests through the Xilinx University Program for academic and research pur- 
poses. The program focuses on and provides prefabricated labs for the Basys3 and NEXYS4DDR, and Zybo boards. For more information, refer to Xilinx's website [17].

Popular boards featuring a Xilinx device are listed in Table 5. The table is roughly sorted by the listed price. For more information about a particular board, see the reference next to the board name.

Table 5. Xilinx Development Boards

\begin{tabular}{|c|c|c|c|c|c|c|c|c|c|}
\hline Board & $\$$ & IC & $\mathbf{L C}$ & Clk & $\begin{array}{l}\text { SW/ } \\
\text { BTN }\end{array}$ & LED & 7seg & $\begin{array}{l}\text { VGA/ } \\
\text { HDMI }\end{array}$ & Features \\
\hline $\begin{array}{c}\text { Numato } \\
\text { Mimas } \\
{[18]}\end{array}$ & 35 & Spartan 6 & $9 \mathrm{~K}$ & $\begin{array}{c}100 \\
\mathrm{MHz}\end{array}$ & - & - & - & - & 16MB SPI Flash \\
\hline $\begin{array}{c}\text { Papilio } \\
\text { One 250k } \\
{[19]}\end{array}$ & 38 & $\begin{array}{c}\text { Spartan } \\
3 \mathrm{E}\end{array}$ & $5 \mathrm{~K}$ & $\begin{array}{c}32 \\
\mathrm{MHz}\end{array}$ & - & - & - & - & $\begin{array}{l}\text { 4MB SPI Flash, } \\
\text { USB-UART } \\
\text { bridge, "Wing" } \\
\text { add-on boards }\end{array}$ \\
\hline $\begin{array}{l}\text { Numato } \\
\text { Mimas } \\
\text { V2 [20] }\end{array}$ & 50 & Spartan 6 & $9 \mathrm{~K}$ & $\begin{array}{c}100 \\
\mathrm{MHz}\end{array}$ & $8 / 2$ & 8 & 3 & Yes & $\begin{array}{c}512 \mathrm{MB} \\
\text { LPDDR, 16MB } \\
\text { SPI Flash, Audio } \\
\text { out, microSD, } \\
\text { Lots of module } \\
\text { add-on boards }\end{array}$ \\
\hline $\begin{array}{l}\text { Snicker- } \\
\text { doodle } \\
{[21][22]}\end{array}$ & 55 & $\begin{array}{c}\text { Zynq } \\
\text { Z-7010 }\end{array}$ & $28 \mathrm{~K}$ & $\begin{array}{l}33.33 \\
\mathrm{MHz}\end{array}$ & $0 / 2$ & 5 & - & 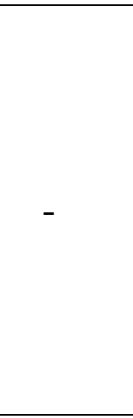 & $\begin{array}{c}\text { ARM dual-core, } \\
\text { WIFI, Bluetooth } \\
\text { 4.0LE, 1GB } \\
\text { RAM, 16MB } \\
\text { Flash, ADC, } \\
\text { DAC, UART, } \\
\text { SPI, microSD, } \\
\text { FreeRTOS }\end{array}$ \\
\hline $\begin{array}{c}\text { Cmod } \\
\text { A7-15T } \\
{[23]}\end{array}$ & 75 & Artix 7 & $16 \mathrm{~K}$ & $\begin{array}{c}100 \\
\mathrm{MHz}\end{array}$ & $0 / 2$ & 3 & - & 更 & $\begin{array}{c}\text { 512k SRAM, } \\
\text { 2MB user SPI } \\
\text { Flash, DIP } \\
\text { breadboarding } \\
\text { layout, } \\
\text { USB-JTAG, } \\
\text { USB-UART } \\
\text { bridge, } 2 \text { Analog } \\
\text { inputs }\end{array}$ \\
\hline
\end{tabular}


Table 5 - continued from previous page

\begin{tabular}{|c|c|c|c|c|c|c|c|c|c|}
\hline Board & $\$$ & IC & LC & Clk & $\begin{array}{l}\text { SW/ } \\
\text { BTN }\end{array}$ & LED & 7seg & $\begin{array}{l}\text { VGA/ } \\
\text { HDMI }\end{array}$ & Features \\
\hline $\begin{array}{c}\text { Mini- } \\
\text { spartan } \\
6+[24] \\
{[25]}\end{array}$ & 75 & Spartan 6 & $9 \mathrm{~K}$ & $\begin{array}{c}50 \\
\mathrm{MHz}\end{array}$ & $4 / 0$ & 8 & - & Yes & $\begin{array}{l}\text { 32MB SDRAM, } \\
64 \text { Mbit SPI } \\
\text { Flash, microSD, } \\
\text { USB-JTAG, } \\
\text { Audio out, 8-CH } \\
\text { ADC }\end{array}$ \\
\hline $\begin{array}{c}\text { Basys3 } \\
{[26],[27]}\end{array}$ & $79 *$ & Artix 7 & $33 \mathrm{~K}$ & $\begin{array}{c}100 \\
\mathrm{MHz}\end{array}$ & $\begin{array}{c}16 / \\
5\end{array}$ & 16 & 4 & Yes & $\begin{array}{c}32 \mathrm{MB} \text { SPI } \\
\text { Flash, ADC, } \\
\text { USB-UART } \\
\text { bridge, USB host } \\
\text { port }\end{array}$ \\
\hline $\begin{array}{c}\text { Mojo V3 } \\
\text { [28] }\end{array}$ & 80 & Spartan 6 & $9 \mathrm{~K}$ & $\begin{array}{c}50 \\
\mathrm{MHz}\end{array}$ & $-1-$ & 8 & - & 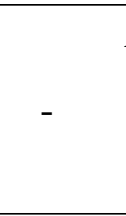 & $\begin{array}{l}\text { ATmega32U4 for } \\
\text { config and } \\
\text { analog read, } \\
\text { 4MB SPI Flash }\end{array}$ \\
\hline Arty [29] & 99 & Artix 7 & $33 \mathrm{~K}$ & $\begin{array}{c}100 \\
\mathrm{MHz}\end{array}$ & $4 / 4$ & 8 & - & (1) & $\begin{array}{c}\text { ADC, 256MB } \\
\text { DDR3, 16MB } \\
\text { SPI Flash, } \\
\text { Ethernet, } \\
\text { USB-UART } \\
\text { bridge, } \\
\text { Arduino/chipKIT } \\
\text { headers }\end{array}$ \\
\hline $\begin{array}{c}\text { Zybo } \\
{[27],[30]}\end{array}$ & $125^{*}$ & $\begin{array}{l}\text { Zynq } \\
7000\end{array}$ & $28 \mathrm{~K}$ & $\begin{array}{c}50 \\
\mathrm{MHz}\end{array}$ & $5 / 6$ & 5 & - & Yes & $\begin{array}{c}\text { Hard core ARM } \\
\text { SoC, } 512 \mathrm{MB} \\
\text { DDR3, } 128 \mathrm{MB} \\
\text { Serial Flash, } \\
\text { USB, microSD, } \\
\text { ADC, Audio }\end{array}$ \\
\hline $\begin{array}{c}\text { Nexys } 4 \\
\text { DDR } \\
{[27],[31]}\end{array}$ & $159 *$ & Artix 7 & $15 \mathrm{~K}$ & $\begin{array}{c}100 \\
\mathrm{MHz}\end{array}$ & $\begin{array}{c}16 / \\
5\end{array}$ & 18 & 8 & Yes & $\begin{array}{l}240 \text { DSP slices, } \\
\text { Accelerometer, } \\
\text { 128MiB DDR2, } \\
\text { 128MiB Serial } \\
\text { Flash, Audio out, } \\
\text { Temp, microSD, } \\
\text { USB host port }\end{array}$ \\
\hline
\end{tabular}

* Academic pricing 


\subsubsection{Evaluation of Xlinx FPGA Boards}

\section{Numato Mimas}

The regular Mimas board has slim features, but does provide four buttons and eight LEDs, unlike the Papilio One 250k board, making it a simple but solid foundation on which you might build your own peripheral boards [18]. This board might be a good hybrid for those who want students to assemble pieces of the course hardware while also reducing cost, time, and complexity. Note that the OwlBoard developed at Oregon Institute of Technology discussed in section 4.3 is based off of the Numato Mimas board.

While this board might work well for lower-level coursework, the need to build or buy external hardware can become cumbersome and expensive. Pluggable add-on boards or expansion modules can be purchased from Numato or other vendors, but these costs can add up quickly, nullifying the cost benefit of this simple, cheap board. If you are already exploring prefabricated board options, then a platform with more on-board, pre-wired components may be a better fit.

See Section 5.2.2 regarding the ISE requirement to program Spartan 6 FPGAs.

\section{Papilio One 250k}

Features on this board are lacking. The SPI flash is on the small side, but should be sufficient for most instructional designs. The irregularly aligned headers, designed for the Gadget Factory's add-on breakout boards called "Wings", could be awkward if a perfboard breakout will be constructed. The smaller Spartan 3E FPGA runs short on logic cells if a large design will be designed as part if the course material. See Section 5.2.2 regarding the ISE requirement to program older Xilinx FPGAs.

Being a basic board with no on-board LEDs or buttons to test or demonstrate basic logic designs, the Papilio is essentially a $\$ 38$ breakout board for an FPGA. By raising the budget by $\$ 12$ or more, you will find boards sporting basic I/O options like LEDs that also have faster clocks and newer, larger FPGAs. If you are looking into simple FPGA boards, then the cheaper Mimas board might fit your bill, with four times the flash memory, a faster clock, and basic I/O devices.

Numato Mimas V2

The Numato Mimas V2 is an expanded version of the Mimas board which features a Spartan 6 FPGA. The Mimas V2 adds components like seven-segment LED displays and an audio output peripheral to the base Mimas platform. The eight common-cathode LEDs would be intuitive for students. The three-digit, seven-segment display is multiplexed, which may affect the instruction or lab time needed for students to properly interface with it [20].

If you would prefer a basic PLD breakout board, then you may consider the regular Mimas board for $\$ 15$ less [18].

See Section 5.2.2 regarding the ISE requirement to program Spartan 6 FPGAs. 


\section{Snickerdoodle}

This board aims to pack as many features into a small, affordable package as it can. In the spirit of targeting hobbyist and maker communities, it is an open source hardware design [22]. The Zynq SoC by itself, being compatible with Vivado WebPACK and housing a dual-core ARM processor and FPGA all in one chip, is a versatile platform. The list of on-board peripherals covers almost all of the essential devices and topics you might consider teaching.

The documentation currently available for this board is limited. The user manual currently focuses on programming and configuring the platform via their custom wireless interface instead of using the Xilinx design suite Vivado. It may be possible to reference Digilent's documentation for their Zybo board to get started with the SoC, as both boards use a Zynq-7010 device. The Snickerdoodle Crowd Source page mentions that the free e-book, "The Zynq Book", may be a useful resource for getting started [32].

Supply and production chains might currently be a concern if integrating this platform into your curriculum. It is unclear how long the designers intend to sell this platform or how much support they might provide. In addition, the base-level Snickerdoodle board is sold out in their crowd sourcing campaign and there does not seem to be another way to order the board [22]. For these reasons, it might be best to look elsewhere until this project matures.

Since this board is so complex and the design is open-source, it would certainly be possible to use their design files and strip out any unnecessary components, add some additional LEDs and buttons, re-route, and spin your own custom PCB.

\section{Cmod A7-15T}

This board is one of the smallest boards mentioned in this paper. The most prominent feature of this board is its DIP layout, made to plug into a solderless breadboard. The board itself only has three LEDs (one of which is an RGB LED) and two pushbuttons, which could introduce unnecessary complexity if more LEDs and buttons are needed [23].

While the increased logic element count is desirable for large projects, almost any I/O device required must be connected externally through a breadboard, perf-board, or custom add-on board. Platforms with many more on-board I/O options are available at competitive prices. Unless your coursework focuses largely on memory or processing-intensive applications or you intend to construct your own external peripheral boards, the Cmod A7 board is not recommended.

\section{miniSpartan6+}

This board, designed by Scarab Hardware, has unique take on FPGA development boards. The miniSpartan6+ offers some simple but convenient peripherals like an ADC, a DAC (for audio output), four switches, eight LEDs, and a microSD card slot. The board does route the unused digital pins out to through-hole pads where headers could presumably be soldered. The board is available in either LX9 (9K logic cells) or LX25 (25K logic 
cells) variants of the Spartan 6 FPGA [24].

Scarab Hardware has provided documentation on their website and GitHub repositories but it may not be enough information to get started for those who do not have experience with Xilinx FPGAs or the ISE software. For both documentation and supply concerns, it may be prudent to consider other options.

See Section 5.2.2 regarding the ISE requirement to program Spartan 6 FPGAs.

\section{Basys 3}

The Basys 3, built by Xilinx's preferred hardware partner, Digilent, is designed for the college classroom and is directly compatible with Xilinx's newer design suite, Vivado. The Artix 7 FPGA with its 33K logic cells and 90 DSP slices should be able to handle the vast majority of educational digital hardware designs. The on-board ADC, 16 switches, 16 LEDs, five pushbuttons, four seven-segment displays, and USB A host port give users a great set of peripherals to work with out of the box [26]. At an academic price of $\$ 79$, the Basys 3 is a versatile and affordable platform [27].

Because this board has most of the features and $\mathrm{I} / \mathrm{O}$ devices you might need in a digital hardware class and it supports the most up-to-date software made by the FPGA manufacturer, the Basys 3 may be one of the best choices for academic use.

Mojo V3

While the tutorials from Embedded Micro are clear and well written, the Mojo V3 board does not have enough LEDs or buttons for most coursework requirements. Breakout boards or significant breadboarding work will be needed to interface with any peripherals. There are other boards with a similar price point which offer more features. [28].

See Section 5.2.2 regarding the ISE requirement to program Spartan 6 FPGAs.

Arty With peripherals for both basic and advanced topics ranging from LEDs to Ethernet, this board is a great learning platform. The Artix 7 FPGA has enough resources to support advanced soft-core processors or DSP designs.

One of the most unique features of this board is the two DIP headers, one for Arduino and the other for chipKIT devices. Since the board targets makers and hobbyists, these headers provides a way to interface with popular programmable devices.

Unfortunately there is no academic pricing for the Arty board. Unless an Arduino or chipKIT device is integrated into your curriculum, there are other boards with similar feature sets at a lower academic cost.

Zybo

If curriculum needs both an FPGA and an ARM core, the Zybo board, featuring the Zynq 7010 SoC may be a desirable platform. While the feature set is similar to that of the Nexys 4 or Basys 3 boards, there are fewer buttons and LEDs so this board may not be well suited for teaching basic logic fundamentals. 
This board does have a higher academic price of $\$ 125$ [27]. If you need a hard processor SoC, then this may be a great option. Otherwise, the Basys 3 with a soft-core processor would be a more cost-effective solution.

Nexys 4 DDR

The Nexys 4 DDR with an Artix 7 FPGA has ample features for most class needs. The abundance of switches and LEDs are very useful for simple input and output peripherals. With ADC, Audio DAC, accelerometer, temperature, USB A host, and other peripherals, the board can handle a wide variety of designs without any physical hardware assembly [31].

With an academic price of $\$ 159$, the option may be outside of some curriculum budgets [27]. For a suitable feature set at a reduced price, see the Basys 3 board.

\subsubsection{Note on ISE and Vivado}

If choosing a board with an older Xilinx device, such as the Spartan 6 or Spartan 3E, note that they are only programmable through Xilinx ISE software. This software has been deprecated by Xilinx since 2014 and the latest version available is 14.7 [33]. This may present an issue if the instructor needs to use SystemVerilog, as ISE does not support SystemVerilog. Otherwise, it should not be a concern for those using Verilog, VHDL, or schematic capture.

Also note that Vivado no longer supports schematic capture, so those implementing schematic capture as part of a introductory course may find themselves better served by an Intel product.

\subsubsection{Xilinx Best Value Board}

The best value among Xilinx options is the Basys3 board by Digilent. The board is available at an academic price of $\$ 79$ and incorporates an Artix-7, which means that the board can use Xilinx' latest IDE, Vivado. This board features 33K logic cells, 16 switches, 16 leds, 5 push buttons, and a 4-digit 7 segment display which should be more than sufficient for Digital Logic and Digital Systems design. This board is also convenient since it can be programmed through Vivado directly without a third party tool required by non-Digilent boards.

There are lower cost boards such as the Numato Mimas or the Papillio One 250k at \$35 and $\$ 38$ respectively, but they use the deprecated ISE IDE, and can not be programmed using Xilinx Impact, as was mentioned in Section 5.2.2.

\section{Conclusion}

Regardless of whether a commercial offering is chosen or you decide to develop your own, ensure that the design meets your needs. Are there an adequate number of switches, buttons, and LEDs for your existing lab assignments? How many RGB LEDs are there, and what type of 7-segment display is it? Common anode or cathode? Are they multiplexed? 
If choosing to use an Intel PSG development platform, the DE10-Lite provides best value for a digital logic or digital system design course at \$55. If choosing to use Xilinx FPGA, the Basys 3 provides best value for a digital logic or digital system design course at $\$ 79$. These prices allow a student to purchase the board for use in 2-3 courses. Both boards provide ample number of switches and buttons, multiple 7-segments, a VGA output, as well as other useful features without the need for additional add-on boards. These components are most likely to be used in a Digital Logic or Digital System Design course.

If one desires an Intel board for use throughout the entire curriculum, the DE1-SoC at a cost of $\$ 125$ is a very good choice, as it provides extra features such as an SoC, additional memory, audio, and a microSD card slot while still containing a large number of switches, LEDs, and 7-segments.

For courses such as Digital Logic I and Digital Logic II, instructors can save time and frustration by buying a commercial offering such as the ones outlined in this paper. For courses such as Digital System Design I or II, instructors can improve student engagement through having students build custom boards. It is time consuming, so this would work better at smaller schools.

Developing your own board only makes sense pedagogically if the board will be assembled by the student and board assembly/soldering is part of your curriculum. Having students assemble boards from the BOM, layout, and schematic documentation does increase student engagement. Adding unique features such as RGB LEDs also seems to improve student engagement. Adding a prototyping area for students to wire their own LEDs, buttons, and other components also improves understanding of relationship between the component and how it is connected to the FPGA. If choosing to develop your own board, the design documentation and files for the boards mentioned in this document are freely available at http://www.oit.edu/ academics/degrees/computer-engineering-technology/open-source-projects.

If the instructor or department is considering building their own boards to save money, they should reconsider not doing so. The vendors listed in this document are far more capable of delivering a reliable product at low cost with reasonable support. Save faculty time and energy for pedagogy and development of course content. If building development boards aligns with your pedagogical objectives, it can be a very valuable and engaging process for your students.

\section{Trademark Information}

Altera, the Altera logo, Cyclone, the Cyclone logo, Intel, the Intel logo, the Intel Inside logo, MAX, Nios, Quartus, and the Quartus logo, are trademarks of Intel Corporation or its subsidiaries in the U.S. and/or other countries.

Xilinx, the Xilinx logo, Artix, ISE, Spartan, Virtex, Vivado, WebPACK, and Zynq are registered trademarks of XilinX.

ARM, Cortex, and the ARM, ARM Powered, ARM Connected Partner, and ARM Connect Community Partner logos are trademarks of ARM Ltd. 
HDMI and High-Definition Multimedia Interface are trademarks of HDMI Licensing LLC.

The USB logo is a trademark of Universal Serial Bus Implementers Forum, Inc.

\section{References}

[1] USB-Blaster - sa89a.net, sa89.net. [Online]. Available: http://www.sa89a.net/mp.cgi/ele/ ub.htm (Retrieved: 06/17/2016).

[2] USB Blaster Download Cable, Terasic Incorporated. [Online]. Available: http ://www. terasic.com.tw/cgi-bin/page/archive.pl?No=46 (Retrieved: 02/11/2017).

[3] JTAG-USB Cable, Digilent Incorporated. [Online]. Available: http://store.digilentinc.com/ jtag-usb-cable (Retrieved: 01/05/2017).

[4] UM232H-B Breakout Module, Future Technology Devices International. [Online]. Available: http://www.ftdichip.com/Products/Modules/DevelopmentModules.htm\#UM232H (Retrieved: 01/05/2017).

[5] xc3sprog, Oct. 7, 2011. [Online]. Available: http://xc3sprog. sourceforge.net/ (Retrieved: 01/05/2017).

[6] DEO User Manual, version 1.6, Terasic Technologies, 53 pp. [Online]. Available: http : $/ /$ www.terasic.com.tw/cgi-bin/page/archive_download.pl?Language $=$ English $\& N o=364 \&$ FID=0c266381d75ef92a8291c5bbdd5b07eb (Retrieved: 01/21/2017).

[7] Acquisition of Altera, Intel Corporation, Jun. 1, 2015, p. 7, 16 pp. [Online]. Available: https://simplecore.intel.com/newsroom/wp-content/uploads/sites/11/2016/03/IntelInvestor-Conference-Call-Deck.pdf (Retrieved: 02/11/2017).

[8] Getting Started - Intel FPGA University Program for Professors, Intel Corporation. [Online]. Available: https://www. altera.com/support/training/university/getting-startedprofessors.html (Retrieved: 02/07/2017).

[9] BEMICROMAX10, Arrow Electronics Incorporated. [Online]. Available: https ://www. arrow.com/en/products/bemicromax10/arrow-development-tools (Retrieved: 01/05/2017).

[10] Altera Cyclone IV FPGA Development Board, LogiFind. [Online]. Available: http : // logifind.com/fpga-cpld-dsp/altera-cyclone-iv-fpga-development-board-ep4ce6e 22c8n1172.html (Retrieved: 01/23/2017).

[11] DE10-Lite User Manual, version 1.3, Terasic Incorporated, Nov. 21, 2016. [Online]. Available: http://www.terasic.com.tw/cgi-bin/page/archive_download.pl?Language=English\& No=1021\&FID=a13a2782811152b477e60203d34b1baa (Retrieved: 01/22/2017).

[12] DE0-Nano Development and Education Board, Terasic Incorporated. [Online]. Available: http://de0-nano.terasic.com (Retrieved: 01/05/2017).

[13] DE0-Nano-SoC Kit, Terasic Incorporated. [Online]. Available: http://de0-nano-soc.terasic. com/ (Retrieved: 01/22/2017). 
[14] DE0-CV Board, Terasic Incorporated. [Online]. Available: http:// de0 - cv.terasic.com (Retrieved: 01/22/2017).

[15] BEMICROCVA9, Arrow Electronics Incorporated. [Online]. Available: https://www.arrow. com/en/products/bemicrocva9/arrow-development-tools (Retrieved: 01/22/2017).

[16] DE0-Nano-SoC Kit, Terasic Incorporated. [Online]. Available: http://de1-soc.terasic.com (Retrieved: 01/22/2017).

[17] Course Materials, Xilinx Corporation. [Online]. Available: https ://www .xilinx .com/ support/university/course-materials.html (Retrieved: 02/01/2017).

[18] Mimas - Spartan 6 FPGA Development Board User Manual, Numato Lab, Feb. 18, 2016. [Online]. Available: https://docs.numato.com/doc/mimas-spartan-6-fpga-developmentboard/ (Retrieved: 02/03/2017).

[19] Papilio One 250K - Low Cost Xilinx FPGA Dev Board, Gadget Factory. [Online]. Available: http://store.gadgetfactory.net/papilio-one-250k-low-cost-xilinx-fpga-dev-board/ (Retrieved: 02/01/2017).

[20] Mimas V2 Spartan 6 FPGA Development Board with DDR SDRAM, Numato Lab. [Online]. Available: http://numato.com/mimas-v2-spartan-6-fpga-development-board-withddr-sdram/ (Retrieved: 02/01/2017).

[21] Snickerdoodle User Manual, krtkl. [Online]. Available: https://github.com/krtkl/snickerdoodlemanual/raw/master/snickerdoodle-user-manual.pdf (Retrieved: 02/01/2017).

[22] Snickerdoodle: Create Something Different, Crowd Supply. [Online]. Available: https : //www.crowdsupply.com/krtkl/snickerdoodle (Retrieved: 02/01/2017).

[23] Cmod A7: Breadboardable Artix-7 FPGA Module, Digilent Incorporated. [Online]. Available: http://store.digilentinc.com/arty-artix-7-fpga-development-board-for-makers-andhobbyists/ (Retrieved: 02/01/2017).

[24] miniSpartan6+, Scarab Hardware. [Online]. Available: https:/www.scarabhardware.com/ minispartan6/ (Retrieved: 02/05/2017).

[25] miniSpartan6-plus/projects/miniSpartan6-plus.ucf, Scarab Hardware. [Online]. Available: https://github.com/scarabhardware/miniSpartan6-plus/blob/master/projects/miniSpartan6plus.ucf (Retrieved: 02/01/2017).

[26] Basys 3 Artix-7 FPGA Trainer Board: Recommended for Introductory Users, Digilent Incorporated. [Online]. Available: http://store.digilentinc.com/basys-3-artix-7-fpga-trainerboard-recommended-for-introductory-users/ (Retrieved: 01/29/2017).

[27] Digilent Academic Price List, Digilent Incorporated. [Online]. Available: https://resource. digilentinc.com/downloads/Academic_Prices.pdf (Retrieved: 02/01/2017).

[28] Mojo V3, Embedded Micro. [Online]. Available: https://embeddedmicro.com/products/ mojo-v3.html (Retrieved: 01/29/2017). 
[29] Arty Artix-7 FPGA: Development Board for Makers and Hobbyists, Digilent Incorporated. [Online]. Available: http://store.digilentinc.com/arty-artix-7-fpga-development-board-formakers-and-hobbyists/ (Retrieved: 02/01/2017).

[30] Zybo Zynq-7000 ARM/FPGA SoC Trainer Board, Digilent Incorporated. [Online]. Available: http://store.digilentinc.com/zybo-zynq-7000-arm-fpga-soc-trainer-board/ (Retrieved: 01/29/2017).

[31] Nexys 4 DDR Artix-7 FPGA: Trainer Board Recommended for ECE Curriculum, Digilent Incorporated. [Online]. Available: http://store.digilentinc.com/nexys-4-ddr-artix-7-fpgatrainer-board-recommended-for-ece-curriculum/ (Retrieved: 01/29/2017).

[32] L. Crockett, R. Elliot, M. Enderwitz, and R. Stewart, The Zynq Book: Embedded Processing with the ARM Cortex-A9 on the Xilinx Zynq-7000 All Programmable SoC. Strathclyde Academic Media, Jul. 14, 2014, 484 pp., IsBn: 978-0-9929787-0-9. PDF Avaliable: http: //www.zynqbook.com.

[33] Downloads, Xilinx Corporation. [Online]. Available: https://www.xilinx.com/support/ download/index.html/content/xilinx/en/downloadNav/design - tools . html (Retrieved: 02/11/2017). 